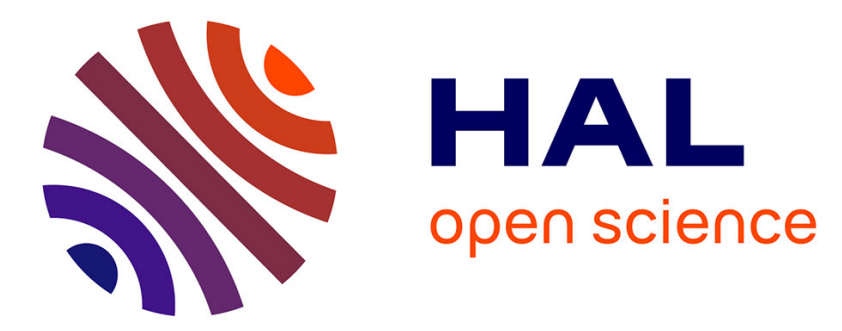

\title{
Sulfur scavenging in a mesoscale model with quasi-spectral microphysics: Two-dimensional results for continental and maritime clouds
}

N. Chaumerliac, E. Richard, Jean-Pierre Pinty, E. Nickerson

\section{- To cite this version:}

N. Chaumerliac, E. Richard, Jean-Pierre Pinty, E. Nickerson. Sulfur scavenging in a mesoscale model with quasi-spectral microphysics: Two-dimensional results for continental and maritime clouds. Journal of Geophysical Research, 1987, 92 (D3), 10.1029/JD092iD03p03114 . hal-01819469

\author{
HAL Id: hal-01819469 \\ https://hal.uca.fr/hal-01819469
}

Submitted on 18 Mar 2021

HAL is a multi-disciplinary open access archive for the deposit and dissemination of scientific research documents, whether they are published or not. The documents may come from teaching and research institutions in France or abroad, or from public or private research centers.
L'archive ouverte pluridisciplinaire HAL, est destinée au dépôt et à la diffusion de documents scientifiques de niveau recherche, publiés ou non, émanant des établissements d'enseignement et de recherche français ou étrangers, des laboratoires publics ou privés. 


\title{
Sulfur Scavenging in a Mesoscale Model With Quasi-Spectral Microphysics: Two-Dimensional Results for Continental and Maritime Clouds
}

\author{
N. Chaumerliac, E. Richard, AND J.-P. Pinty \\ Laboratoire Associe de Meteorologic Physique, Clermont-Ferrand, France
}

\author{
E. C. Nickerson
}

National Oceanic and Atmospheric Administration, Environmental Research Laboratories, Boulder, Colorado

\begin{abstract}
A three-dimensional mesoscale numerical model (Nickerson et al., 1986) with quasi-spectral microphysics has been extended to include gas and aerosol removal by cloud droplets and raindrops. Combining meteorological predictions and pollutant scavenging parameterizations, two-dimensional sensitivity tests have been carried out for continental and maritime clouds over an idealized topography. Nucleation scavenging is the most efficient in-cloud removal mechanism; however, differences in cloud droplet spectra between continental and maritime clouds lead to differences in their scavenging efficiencies for gases and aerosols, thereby emphasizing the need for the simultaneous treatment of meteorological and physicochemical processes.
\end{abstract}

\section{INTRODUCTION}

Wet deposition is the result of complex nonlinear interactions between meteorological and physicochemical factors. Identification and knowledge of those interactive processes have been significantly improved in recent years as a result of field investigations, laboratory studies, and theory aided by numerical simulations. Some numerical studies [Hegg et al., 1984b; Tremblay and Leighton, 1984; Kitada et al., 1984] concentrate on the redistribution of trace gases and aerosols by various precipitating cloud systems. In such models, meteorological fields are usually prespecified under the assumption of steady airflows [Tremblay and Leighton, 1984] or by objective analysis of the wind field [Kitada et al., 1984]. Moreover, cloud microphysics is only grossly parameterized, thus excluding any explicit calculation of the scavenging rates [Hegg et al., 1984b], since nucleation and capture rates are strongly dependent on hydrometeor and aerosol spectra.

The aim of this paper is to exemplify the usefulness of a quasi-spectral parameterization of liquid water and aerosols so as to describe nucleation scavenging and $\mathrm{SO}_{2}$ dissolution into cloud droplets. A microphysical scheme, with raindrop spectra only, has already been incorporated into a threedimensional mesoscale model [Nickerson et al., 1986] [or simulating precipitation. Here we present an extended microphysical version of this scheme allowing for an improved explicit representation of the condensation/evaporation processes. Two-dimensional simulations are next performed to evaluate the relative contributions of each scavenging process in typical continental and maritime clouds.

\section{Model Presentation}

\subsection{Description of Meteorological Model}

The three-dimensional hydrostatic mesoscale model is based upon primitive equation resolution. The horizontal grid length is typically $10 \mathrm{~km}$ and the time step is $10 \mathrm{~s}$. There are 15 computational levels in the vertical, equally spaced in a

Copyright 1987 by the American Geophysical Union.

Paper number 6D0701.

0148-0227/87/006D-0701\$05.00 terrain-following ( $n u$ ) coordinate system. A centered leap-frog scheme is used with an Asselin [1972] filter. Lateral boundary conditions are of the Orlanski [1976] type for the normal velocity component. The tangential velocity and all other prognostic variables are computed using advective conditions on outflow boundaries and prescribed values at inflow points. A viscous damping layer at the top of the domain [Klemp and Lilly, 1978] is used to absorb vertically propagating waves. A comprehensive description of the dynamical computations of the model can be found in the work by Nickerson et al. [1986].

The prognostic variables in the warm-rain version of the model are ground pressure $\Pi$, horizontal wind $(u, v)$, vapor mixing ratio $q_{v}$, and potential temperature $\Theta$. Here $\Theta$ is predicted in flux form as

$$
\begin{aligned}
\frac{\partial(\Pi \Theta)}{\partial t}=-\frac{\partial}{\partial x}(\Theta \Pi u)-\frac{\partial}{\partial y} & (\Theta \Pi v)-\frac{\Pi}{\sigma^{\prime}} \frac{\partial}{\partial v}\left(\sigma^{\prime} \Theta \dot{v}\right) \\
& +\left.\frac{L_{v} \Pi}{C_{p m} \hat{P}} \frac{\partial q_{v}}{\partial t}\right|_{\substack{\text { condensation } \\
\text { evaporation }}}+F_{\Theta}
\end{aligned}
$$

Predictions are made of both rainwater mixing ratio $q_{r w}$ and total number concentration $N_{r w}$, assuming a lognormal drop distribution. Extensive use of Berry and Reinhardt's [1973] formulation has been made for parameterization of the autoconversion, accretion, and self-collection processes. For further details, the reader is referred to Nickerson et al. [1986].

Cloud droplets are also assumed to be lognormally distributed. In the diameter range $D$ to $D+d D$, the cloud droplet concentration is given by

$$
d N_{c w}=\frac{N_{c w}}{(2 \pi)^{1 / 2} \sigma_{c} D} \exp \left(-\frac{1}{2 \sigma_{c}{ }^{2}} \ln ^{2} \frac{D}{D_{c 0}}\right) d D
$$

where $N_{c w}$ is the total number concentration of droplets; $D_{c o}$, the modal diameter; and $\sigma_{c}$, the dispersion parameter. Integration of (2) over the entire droplet spectrum yields the following expression for $q_{c w}$, the cloud water mixing ratio:

$$
q_{c w}=\frac{N_{c w}}{\rho_{a}}\left(\frac{\pi}{6} D_{c_{0}}{ }^{3} \rho_{w}\right) \exp \left(\frac{9}{2} \sigma_{c}^{2}\right)
$$




\section{Microphysical processes}

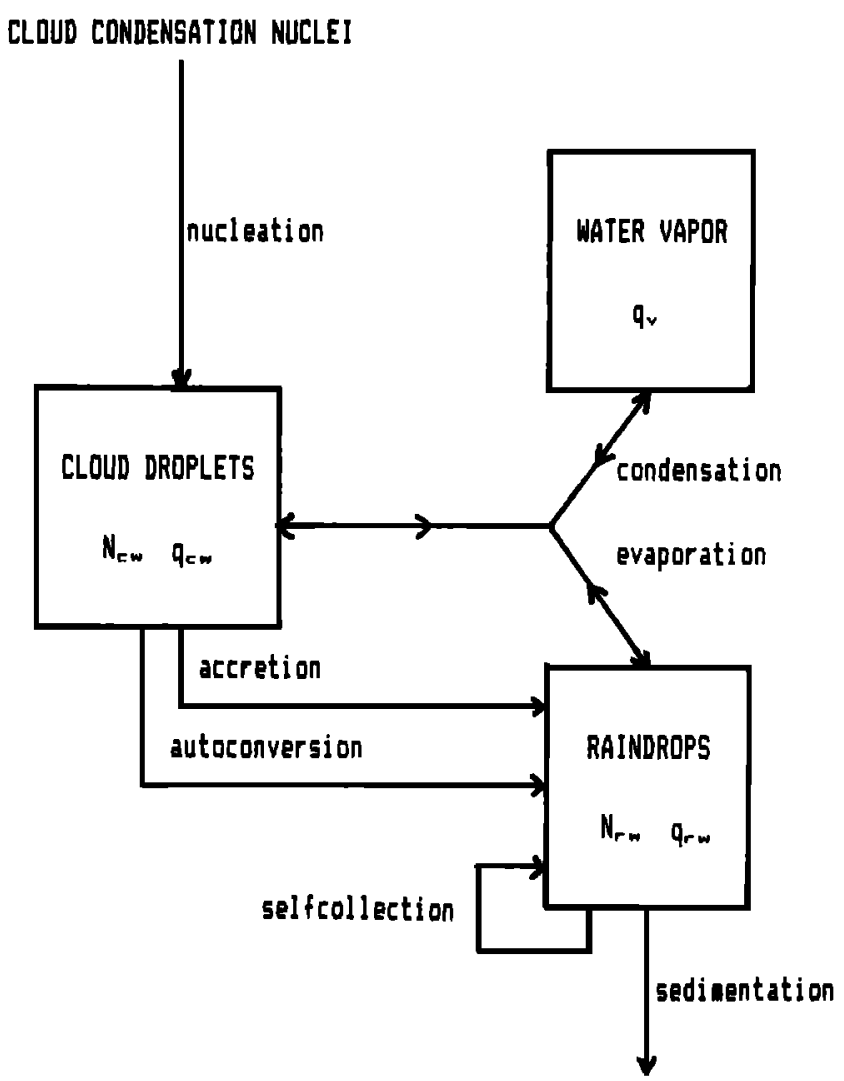

Fig. 1. Synopsis of the microphysical processes in the mesoscale model.

where $\rho_{a}$ and $\rho_{w}$ are the densities of air and liquid water, respectively. To close the system of (2) and (3), $\sigma_{c}$ is assumed constant, equal to 0.15 (continental case) or to 0.28 (maritime case). Those values are taken from Berry and Reinhardt [1973], where $\sigma_{c}$ is deduced from the expression of the relative variance of the cloud droplet spectrum number density function. Predicting $N_{c w}$ and $q_{c w}$, as for the rainwater, $D_{c_{0}}$ is then computed from (3).

The microphysical processes to be considered are schematically depicted in Figure 1. The number of condensation nuclei active at supersaturation $S$, is given by

$$
N=C S^{k}
$$

where $C$ and $k$ are empirical constants. For continental clouds, $C$ is set to $3500 \mathrm{~cm}^{-3}$ and $k$ to 0.9 , while for maritime clouds $C=100$ and $k=0.7$. These experimental values have been adopted as being typical of maritime and continental clouds in different parts of the world [Pruppacher and Klett, 1978].

From (4) the number of cloud condensation nuclei activated per second is derived. It is equal to the time change of the number of cloud droplets formed through heterogeneous nucleation. It is not possible to calculate this number directly, since the time constant of the equation for $d S / d t$ can be less than $0.1 \mathrm{~s}$ and so is much smaller than the time step of the model, $\Delta t=10 \mathrm{~s}$. Following $T$ womey [1959], an upper bound for the supersaturation $S_{\max }$ is calculated which gives the maximum number of activated nuclei and the number of cloud droplets formed through nucleation during every time step. This calculation is quite similar to the one reported by Pruppacher and Klett [1978]:

$$
S \leq\left\{\frac{\rho_{a}\left[A_{1}(d P / d t)\right]^{3 / 2}}{2 \pi \rho_{w} k C A_{2} A_{3}{ }^{3 / 2} \beta[(k / 2),(3 / 2)]}\right\}^{1 /(k+2)}
$$

where

$$
\begin{aligned}
& A_{1}=\frac{1}{P}-\frac{\varepsilon L_{v}}{R T^{2} \rho_{a} C_{p}} \\
& A_{2}=\frac{1}{q_{v s}}+\frac{\varepsilon L_{v}{ }^{2}}{R T^{2} C_{p}}
\end{aligned}
$$

and

$$
A_{3}=\frac{L_{v} \rho_{w}}{K T}\left(\frac{L_{v}}{R_{w} T}-1\right)+\frac{\rho_{w} R_{w} T}{e_{s w}(T) D_{v}}
$$

Symbols and units are given in the appendix.

The nucleation term is finally taken into account by adding to the predicted value of $N_{c w}$ the term $N_{\text {nuc }}$ given by

$$
N_{\text {nuc }}=\max \left(C S_{\max }{ }^{k}-N_{c w \cdot \text { lotal }}, 0\right)
$$

where $N_{c w \cdot \text { total }}$ is the total number of cloud droplets already formed through nucleation. If cloud condensation nuclei have been activated, the newly nucleated cloud droplets have a critical diameter corresponding to the maximum of the supersaturation $S_{\max }$, namely:

$$
D_{\text {crit }}=\left(4 M_{w} \sigma_{w}\right) /\left(3 S_{\max } T R \rho_{w}\right)
$$

The corresponding change in mixing ratio $q_{\text {nuc }}$ is deduced from $N_{\text {nuc }}$ :

$$
q_{\mathrm{nuc}}=\frac{\pi}{6} \frac{\rho_{w}}{\rho_{a}} D_{\mathrm{crit}}^{3} N_{\mathrm{nuc}}
$$

Newly nucleated droplets will in fact grow to a size larger than $D_{\text {cril }}$ over the 10 -s time step, therefore (8) is a lower limit for the change in mixing ratio.

The condensation/evaporation term appears in the latent heat release term (equation (1)) and in the prediction equations for the mixing ratios $q_{v}, q_{c w}$, and $q_{r w}$, according to the following relationship:

$$
\left.\frac{\partial q_{v}}{\partial t}\right|_{\substack{\text { condensation } \\ \text { cvaporation }}}=-\left.\frac{\partial q_{c w}}{\partial t}\right|_{\substack{\text { condensation } \\ \text { evaporation }}}-\left.\frac{\partial q_{r w}}{\partial t}\right|_{\substack{\text { condensation } \\ \text { evaporation }}}
$$

In order to obtain the rate of change of $q_{c w}$ and $q_{r w}$, integration is made over the cloud droplet and raindrop spectra. Calculations are performed first for $q_{c w}$. The rate of change of $q_{c w}$ is expressed by

$$
\frac{\partial q_{c w}}{\partial t}=\frac{\rho_{w}}{\rho_{a}} \int_{0}^{\infty} \frac{\pi}{2} D^{2} \frac{d D}{d t} \frac{N_{c w}}{(2 \pi)^{1 / 2} \sigma_{c} D} \exp \left(-\frac{1}{2{\sigma_{c}}^{2}} \ln ^{2} \frac{D}{D_{c o}}\right) d D
$$

Then, the time rate of change for diameter $D$ of cloud droplets due to condensation or evaporation is

$$
\frac{d D}{d t}=\frac{A_{3} S}{D}
$$


where $A_{3}$ is the thermodynamical function in (5). This leads to

$$
\left.\frac{\partial q_{c w}}{\partial t}\right|_{\substack{\text { condensation } \\ \text { evaporation }}}=\frac{\rho_{w}}{\rho_{a}} \frac{\pi}{2} A_{3} S N_{c w} D_{c_{0}} \exp \frac{\sigma_{c}{ }^{2}}{2}
$$

A similar expression is calculated for

$$
\left.\frac{\partial q_{r w}}{\partial t}\right|_{\substack{\text { condensation } \\ \text { evaporation }}}
$$

apart from the fact that a ventilation factor arises for the time rate of change of raindrop diameter:

$$
\frac{d D_{r}}{d t}=\frac{A_{3} S \bar{f}}{D_{r}}
$$

After Pruppacher and Rasmussen [1979], $\bar{f}$ is parameterized by

$$
\bar{f}=0.78+0.308 X
$$

where $X=R e^{1 / 2} S c^{1 / 3}$.

Then, we have adjusted the variable $X$ as a function of diameter $D_{r}$ by

$$
X=-1.406 \times 10^{6} D^{2}+1.725 \times 10^{4} D-0.675
$$

Replacing $d D_{r} / d t$ by its expression as a function of $D_{r}$ and after integration over the raindrop spectrum, the rate of change of $q_{r w}$ is written as

$$
\begin{aligned}
& \left.\frac{\partial q_{r w}}{\partial t}\right|_{\substack{\text { condensation } \\
\text { evaporation }}}=\frac{\rho_{w}}{\rho_{a}} \frac{\pi}{2} A_{3} S N_{r w}\left[0.572 D_{r o} \exp \left(\sigma_{r}{ }^{2} / 2\right)\right. \\
& \left.+5.31 \times 10^{3} D_{r 0} \exp \left(2 \sigma_{r}{ }^{2}\right)-4.33 \times 10^{5} D_{r 0}{ }^{3} \exp \left(\frac{9}{2} \sigma_{r}{ }^{2}\right)\right]
\end{aligned}
$$

Because of the discrepancy between the model time step and the supersaturation time constant, it is not possible to calculate $S$ exactly in (12) and (16). The scheme of Sakakibara [1979] is used here, because it is adapted for stable computation of the condensation process with a large time step of the order of $10 \mathrm{~s}$. The method consists in solving analytically the following equation:

$$
\frac{d S}{d t}=\left(C_{1}+C_{2}+C_{3}\right) S+C_{3}
$$

where:

$$
\begin{gathered}
C_{1}=-\frac{1}{q_{v s}} \frac{\rho_{w}}{\rho_{a}} \frac{\pi}{2} A_{3} \Sigma \\
C_{2}=-\frac{\varepsilon L_{v}^{2}}{R T^{2} C_{p}} \frac{\rho_{w}}{\rho_{a}} \frac{\pi}{2} A_{3} \Sigma \\
C_{3}=\left(\frac{1}{P}-\frac{\varepsilon L_{v}}{R T^{2} \rho_{a} C_{p}}\right) \frac{d P}{d t}
\end{gathered}
$$

and

$$
\begin{aligned}
& \Sigma=N_{c w} D_{c_{0}} \exp \left({\sigma_{c}}^{2} / 2\right)+N_{r w}\left[0.572 D_{r_{0}} \exp \left(\sigma_{r}{ }^{2} / 2\right)\right. \\
& \left.+5.31 \times 10^{3} D_{r_{0}}{ }^{3} \exp \left(2 \sigma_{r}{ }^{2}\right)-4.33 \times 10^{5} D_{r o}{ }^{3} \exp \left(\frac{9}{2} \sigma_{r}{ }^{2}\right)\right]
\end{aligned}
$$

An approximate average value $\bar{S}$ over the time interval $\Delta t$ is then evaluated as

$$
\bar{S}=-\frac{C_{3}}{C}-\left(s_{0}+\frac{C_{3}}{C}\right)\left(1-\frac{\exp (C \Delta t)}{C \Delta t}\right)
$$

where $S_{0}\left(=q_{v} / q_{v s}-1\right)$ is the supersaturation at the beginning of the time step $\Delta t$ and $C=C_{1}+C_{2}+C_{3}$. This value $\bar{S}$ is used in (12) and (16). The rate of change of $q_{v}$ is

$$
\left.\frac{\partial q_{v}}{\partial t}\right|_{\substack{\text { condensation } \\ \text { evaporation }}}=-\frac{\rho_{w}}{\rho_{a}} \frac{\pi}{2} A_{3} \overline{S \Sigma}
$$

With evaporation the smallest drops of the spectrum can disappear entirely. This explains the sink terms in the equation used for $N_{c w}$ and $N_{r w}$ prediction in case of total evaporation. The term

$$
\left.\frac{\partial N_{c w}}{\partial t}\right|_{\text {evaporation }}
$$

is calculated as in the work by Nickerson et al. and the same expression is used for

$$
\left.\frac{\partial N_{r w}}{\partial t}\right|_{\text {evaporation }}
$$

Based upon a simplified evaluation of supersaturation, these parameterizations for the nucleation and the condensation/evaporation processes allow for explicit calculations of aerosol nucleation rates and dissolution rates of gases in the aqueous phase. This is very important, since these two processes are admittedly the most eflicient among the various pollutant scavenging processes in the troposphere [Garland, 1978]. Another advantage of this quasi-spectral formulation of cloud water is that it allows for a detailed description of three regimes of aerosol capture by raindrops.

\subsection{Aerosol and Gas Scavenging Parameterizations}

As for the hydrometeors, aerosol particles are assumed to be lognormally distributed, the dispersion parameter being set to In 2 [Dana and Hales, 1976]. One discriminates between three categories of particles: those free in the air and others attached to cloud droplets or raindrops, respectively. Only sulfate particles are considered here. An overview of the physicochemical processes is given in Figure 2. Sulfate volume mixing ratio in cloud and rainwater can be increased through conversion of dissolved $\mathrm{SO}_{2}$. Separate prognostic equations are written for each sulfate category for both number concentration and volume mixing ratio. These are listed below:

$$
\begin{gathered}
\frac{\partial \Pi C_{a p}}{\partial t}=-A\left(C_{a p}\right)-\Pi\left(\left.\frac{\partial C_{a p}}{\partial t}\right|_{\substack{\text { Brownian } \\
d 1 \text { 1fusion }}}+\left.\frac{\partial C_{a p}}{\partial t}\right|_{\substack{\text { dynamical } \\
\text { capture }}}\right)+F_{C_{a p}} \\
\frac{\partial \Pi q_{a p}}{\partial t}=-A\left(q_{a p}\right)-\Pi\left(\left.\frac{\partial q_{a p}}{\partial t}\right|_{\substack{\text { Brownian } \\
\text { diffusion }}}+\left.\frac{\partial q_{a p}}{\partial t}\right|_{\substack{\text { dynamical } \\
\text { capture }}}\right)+F_{q_{a p}}
\end{gathered}
$$

$$
\frac{\partial \Pi C_{c p}}{\partial t}=-A\left(C_{c p}\right)+\Pi\left(\left.\frac{\partial C_{a p}}{\partial t}\right|_{\substack{\text { Brownian } \\ \text { diffusion }}}\right.
$$

$$
\left.-\left.\frac{\partial C_{c p}}{\partial t}\right|_{\text {aceretion }}-\left.\frac{\partial C_{c p}}{\partial t}\right|_{\text {autoconversion }}\right)+F_{C_{c p}}
$$

$$
\begin{aligned}
\frac{\partial \Pi q_{c p}}{\partial t} & =-A\left(q_{c p}\right)+\Pi\left(\left.\frac{\partial q_{a p}}{\partial t}\right|_{\substack{\text { Brownian } \\
\text { diffusion }}}-\left.\frac{\partial q_{c p}}{\partial t}\right|_{\text {accretion }}\right. \\
& \left.-\left.\frac{\partial q_{c p}}{\partial t}\right|_{\text {autoconversion }}+\left.\frac{3}{2} \rho_{a} \frac{\partial q_{d s}}{\partial t}\right|_{\text {oxidation }}\right)+F_{q_{c p}}
\end{aligned}
$$




\section{Physicochenical processes}

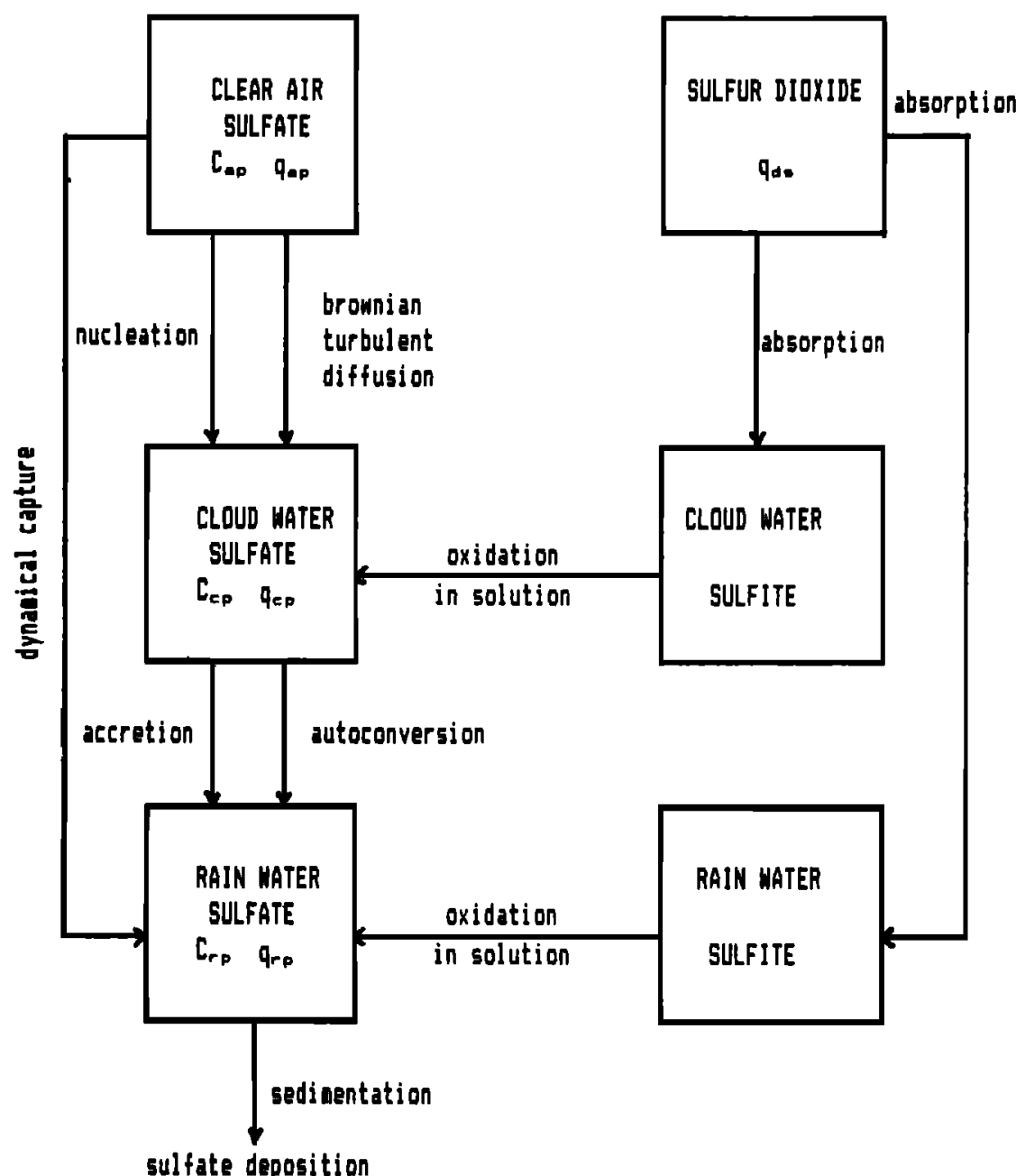

Fig. 2. Synopsis of the physicochemical processes in the mesoscale model.

$$
\begin{aligned}
\frac{\partial \Pi C_{r p}}{\partial t}= & -A\left(C_{r p}\right)+\Pi\left(\left.\frac{\partial C_{a p}}{\partial t}\right|_{\substack{\text { dynamical } \\
\text { capture }}}+\left.\frac{\partial C_{c p}}{\partial t}\right|_{\text {accretion }}\right. \\
& \left.+\left.\frac{\partial C_{c p}}{\partial t}\right|_{\text {autoconversion }}+\left.\frac{\partial C_{r p}}{\partial t}\right|_{\text {sedimentation }}\right)+F_{C_{r p}} \\
\frac{\partial \Pi q_{r p}}{\partial t}= & -A\left(q_{r p}\right)+\Pi\left(\left.\frac{\partial q_{a p}}{\partial t}\right|_{\substack{\text { dynamical } \\
\text { capture }}}+\left.\frac{\partial q_{c p}}{\partial t}\right|_{\text {accretion }}\right. \\
& +\left.\frac{\partial q_{c p}}{\partial t}\right|_{\text {autoconversion }}+\left.\frac{\partial q_{r p}}{\partial t}\right|_{\text {sedimentation }} \\
& \left.+\left.\frac{3}{2} \rho_{a} \frac{\partial q_{d s}}{\partial t}\right|_{\text {oxidation }}\right)+F_{q_{r p}}
\end{aligned}
$$

where the operator $A$ applied to a variable $q$ is defined as

$$
A(q)=\frac{\partial}{\partial x}(q \Pi u)+\frac{\partial}{\partial y}(q \Pi v)+\frac{\Pi}{\sigma^{\prime}} \frac{\partial}{\partial v}\left(\sigma^{\prime} q \dot{v}\right)
$$

The last terms $F$ in (24)-(29) are the friction terms. Each friction term consists, in a vertical eddy diffusion term repre- senting the turbulent transport of a variable within the planetary boundary layer [Nickerson, 1979] and in a horizontal diffusion term, of the form:

$$
\pi K_{H}\left(\frac{\partial^{2}}{\partial x^{2}}+\frac{\partial^{2}}{\partial y^{2}}\right)
$$

operating on a $v$-surface.

Aerosol scavenging by hydrometeors occurs through two different mechanisms. First, aerosols are scavenged through direct capture by raindrops: the associated capture rate is calculated after Dana and Hales [1976]. Second, indirect scavenging can take place through a two-stage process [Pruppacher and Klett, 1978]. In the first stage, most aerosols are incorporated into cloud water by nucleation and by Brownian and turbulent diffusion. In the second stage this polluted cloud water is accreted by falling raindrops or cloud droplets to form larger raindrops. The parameterizations developed for Brownian and turbulent diffusion rates are from Dingle and Lee [1973]. A comprehensive survey for removal rate parameterizations can be found in the work by Chaumerliac et al. [1986]. 


\section{potential temperature $(\mathrm{K})$}

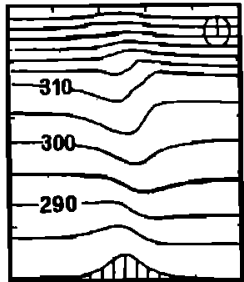

$2790-342.7$

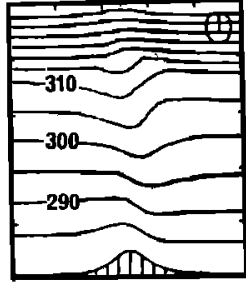

$279.0-342.9$

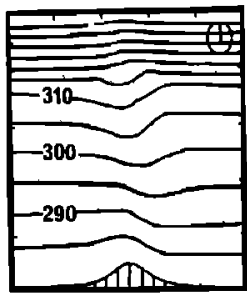

$279.0-3430$

horizontal wind $(\mathrm{m} / \mathrm{s})$

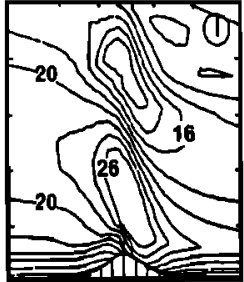

$0-29.9$

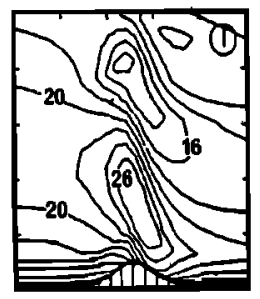

$0-27.9$

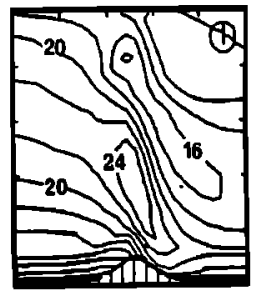

$0-25.9$

vertical velocity $(\mathrm{cm} / \mathrm{s})$
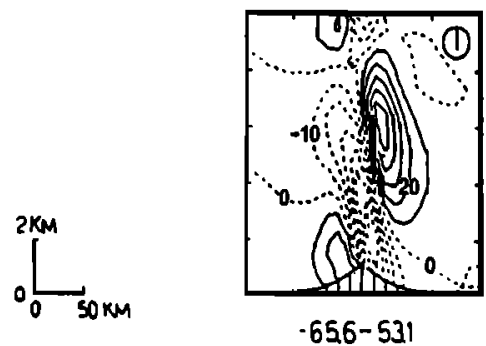

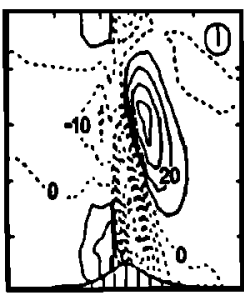

$64.1-425$

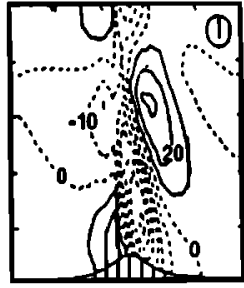

$-651-309$

a)dry

b)continental

\section{c)maritime}

Fig. 3. Potential temperature, horizontal and vertical velocities for (a) dry, (b) continental, and (c) maritime cases in the presence of orography. Extreme values of the isocontours are indicated at the bottom of each figure.

The rates of accretion and autoconversion, for the transfer of cloud water sulfates to rainwater sulfates, are calculated using the microphysical rates with proportionality relationships.

The sedimentation term is formulated as follows:

$$
\left.\frac{\partial C_{r p}}{\partial t}\right|_{\text {sedimentation }}=\frac{\partial}{\partial z}\left(\frac{C_{r p}}{N_{r w}} S_{n}\right)
$$

where $S_{n}$ is the sedimentation flux of raindrops. The term

$$
\left.\frac{\partial q_{r p}}{\partial t}\right|_{\text {sedimentation }}
$$

is formally similar.

The nucleation rates, not appearing in the set of equations (24)-(29) are substracted from $C_{a p}$ and $q_{a p}$ and added to $C_{c p}$ and $q_{c p}$ after every advance in time. The term $C_{a p \cdot n u c}$ is proportional to $N_{\text {nuc }}$ but the term $q_{a p \text {.nuc }}$ has to be calculated by

$$
q_{a p \cdot \text { nuc }}=\frac{4}{3} \pi r_{\text {nuc }}^{3} C_{a p \cdot n u c}
$$

The dry condensation nucleus radius $r_{\text {nuc }}$ is required and is calculated by equating [Prodi and Tampieri, 1982]:

$$
S_{\max } \simeq \frac{8(2 \pi)^{1 / 2}}{9 \rho_{w}}\left(\frac{\sigma m_{w}}{R T}\right)^{3 / 2}\left(\frac{i m m_{w}}{m_{N}}\right)^{-1 / 2}
$$

The nucleus mass $m$, then the dry radius $r_{\text {nuc }}$ are deduced from this relationship.

Considering now gaseous pollutants, prediction is made of the $\mathrm{SO}_{2}$ mixing ratio. Sulfur dioxide is absorbed by cloud droplets and raindrops before being oxidized in solution. Only major $\mathrm{SO}_{2}$ oxidants in aqueous phase, ozone, and hydrogen peroxide are considered here. The formulations of $\mathrm{SO}_{2}$ dissolution and its subsequent oxidation are derived from Hegg et al. [1984b]. $\mathrm{O}_{3}$ and $\mathrm{H}_{2} \mathrm{O}_{2}$ are $50 \mathrm{ppb}$ and $1 \mathrm{ppb}$, respectively, initially in the gas phase and the rates of oxidation of S(IV) are based on Maahs [1983] for $\mathrm{O}_{3}$ and on Martin [1984] for $\mathrm{H}_{2} \mathrm{O}_{2}$. 

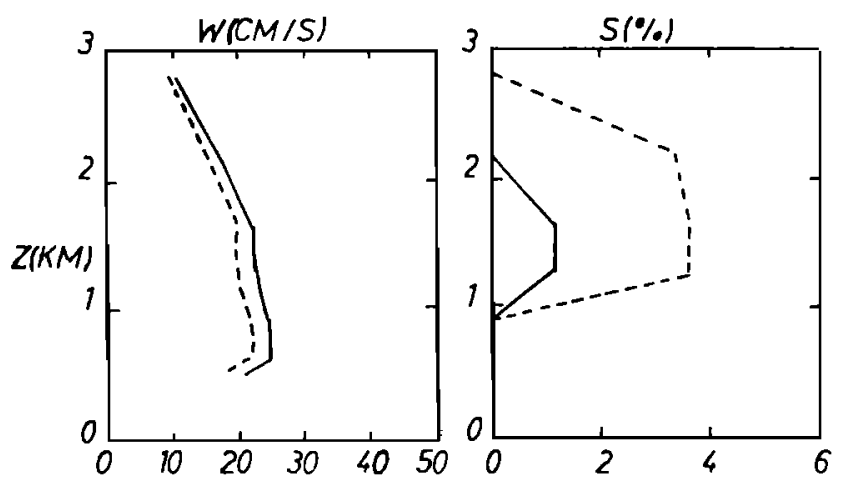

- continental

-.. maritime

Fig. 4. Vertical profiles of vertical velocity and supersaturation for continental clouds (solid lines) and maritime clouds (dashed lines) at $x=110 \mathrm{~km}$

\section{Model Results}

\subsection{Initial Conditions}

In order to test simultaneously the microphysical and physicochemical parameterizations, a series of two-dimensional sensitivity tests were carried out. This choice has been made because two-dimensional simulations are less time consuming than three-dimensional ones and because such idealized tests are well documented as regards to the dynamics [Klemp and Lilly, 1978; Mahrer and Pielke, 1978]. Comparative tests between dry, continental, and maritime conditions have been performed. Because of complex interactions between meteorological and physicochemical processes, such tests are especially useful for identifying the relative contributions of each mechanism.

The model is run over an idealized bell-shaped mountain, 1 $\mathrm{km}$ high and $25 \mathrm{~km}$ in halfwidth. A two-layer atmosphere is considered, with a lower layer of constant lapse rate up to 8 $\mathrm{km}$ and an isothermal layer aloft. The initial horizontal wind speed is uniformly $20 \mathrm{~ms}^{-1}$ and the relative humidity is $80 \%$ below $3 \mathrm{~km}$.

In addition, the $\mathrm{SO}_{2}$ and sulfate variables are initialized with the following exponential profiles [Hegg et al., 1984b]:

$$
\begin{gathered}
q_{d s}(z)=4.3 \times 10^{-9} \exp (-z / 2000) \\
q_{a p}(z)=4 \times 10^{-12} \exp (-z / 3500) \\
C_{a p}(z)=10^{9} \exp (-z / 3500)
\end{gathered}
$$

where $z$ is the altitude, all units being in MKS.

Our selected case is typical of background pollution in Western Europe [Georgii, 1978; Georgii and Meixner, 1980]. Tests to evaluate interactions between microphysical and physicochemical processes together with comparisons between continental and maritime cases are performed over 6-hour simulation periods. In the comparison between continental and maritime clouds, one discriminates between their dynamical features, their spectra, and the relative efficiency with which they can scavenge aerosols and gases.

\subsection{Meteorological Fields}

First, the dynamics of mountain waves are investigated under three cases: dry case (no moisture) as opposed to conti- nental and maritime clouds. Figure $3 a$ displays the results of a dry simulation, while Figures $3 b$ and $3 c$ refer to simulations for continental and maritime cases, respectively. When comparing Figure $3 a$ and Figures $3 b$ and $3 c$, one can observe that moist waves are weaker in amplitude than dry waves [Durran and Klemp, 1983]. Between Figures $3 b$ and $3 c$, noticeable differences appear in the dynamical fields, with larger vertical velocities in the continental case. This is even more obvious for the vertical profiles in Figure 4 where vertical velocities are drawn as a function of height at a selected grid point (one grid point upwind from the mountain top). Vertical supersaturation profiles are reported in Figure 4 . We find that supersaturations in the region of active updrafts are about twice as great in the maritime case as in the continental one. Profiles in Figure 4 are quite comparable to the results of Lee and Pruppacher [1977], in their comparative study of continental and maritime cumuli within the dynamical framework of an entraining air parcel.

In addition to changes in dynamical features, other typical differences between continental and maritime clouds can be found in their spectra, determined from the cloud condensation nuclei spectra. Thus high droplet concentrations $\left(500-600 \mathrm{~cm}^{-3}\right)$ with narrow spectra centered at about $10 \mu \mathrm{m}$, typical of continental clouds have been obtained. The maritime cloud simulated in the model contains about 50 droplets $\mathrm{cm}^{-3}$ with diameter of about $25 \mu \mathrm{m}$. In Figure 5, vertical cross sections of cloud water and rainwater mixing ratios are displayed which reflect the major differences between continental and maritime clouds. Cloud water contents are about twice as large in the continental case, while rainwater contents are considerably larger in the maritime case. Consequently, after 6 hours of model time, one observes in Figure 6 that the maritime cloud rains about 10 times more than the continental cloud and that the maximum of precipitation is not located at the same position in the continental and maritime cases. In Figure 6 there is a slight shift of both the maxima of precipitation, the continental cloud raining farther from the mountain top than the maritime cloud. This is probably due to continental small cloud droplets being more sensitive to advection leading to longer growth times before effective production of rain by coalescence [Squires, 1958].

\subsection{Aerosol Scavenging Results}

Nucleation is widely recognized as the most efficient process among all scavenging mechanisms [Flossmann et al., 1985; Jensen and Charlson, 1984; Radke, 1983; Hegg et al., 1984a]. In order to evaluate the effects of nucleation scavenging, we proceed to two sensitivity tests. In the first run all the scavenging processes are considered, while in the second run the nucleation scavenging term is set equal to zero. These two cases (with and without nucleation) are considered for both maritime and continental clouds. To study the relative efficiency of aerosol scavenging in the two types of clouds, the same initial aerosol distribution is assumed. This vertical profile, typical of continental cases has been specified earlier (see section 3.1, (equations (34)-(35)).

Results are presented in Figures 7 and 8 in the form of vertical cross sections for concentrations of aerosols attached to cloud droplets (Figure 7) and aerosols removed by rain (Figure 8) after a 6-hour run. A large difference in the number of aerosols collected by cloud water is observed between the run accounting only for the dynamical capture of aerosols 


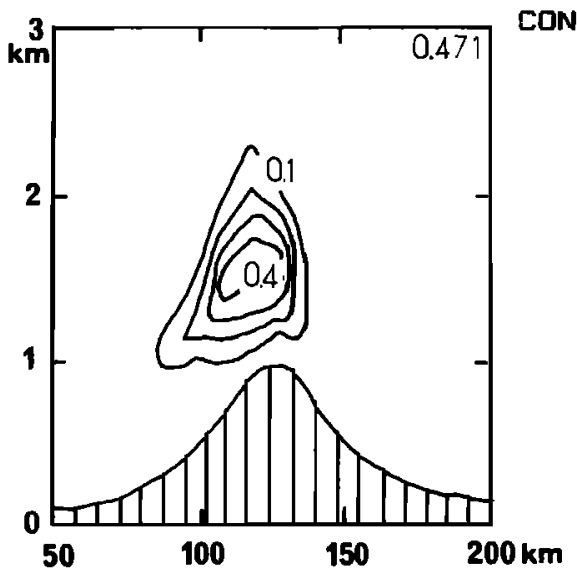

CLOUD WATER

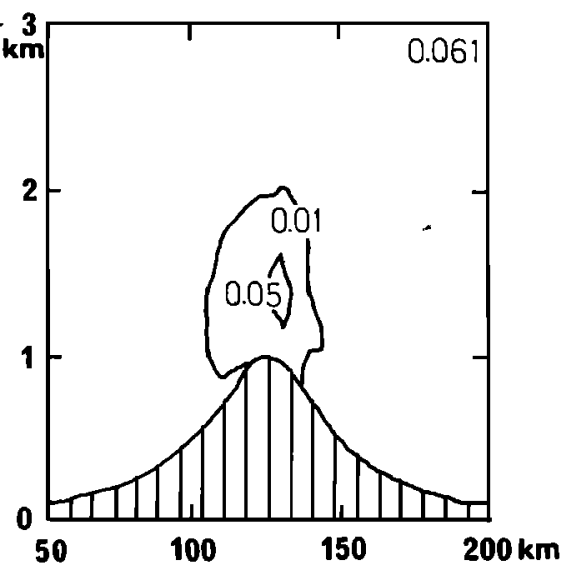

RAINWATER

MIXING RATIOS (G/KG)
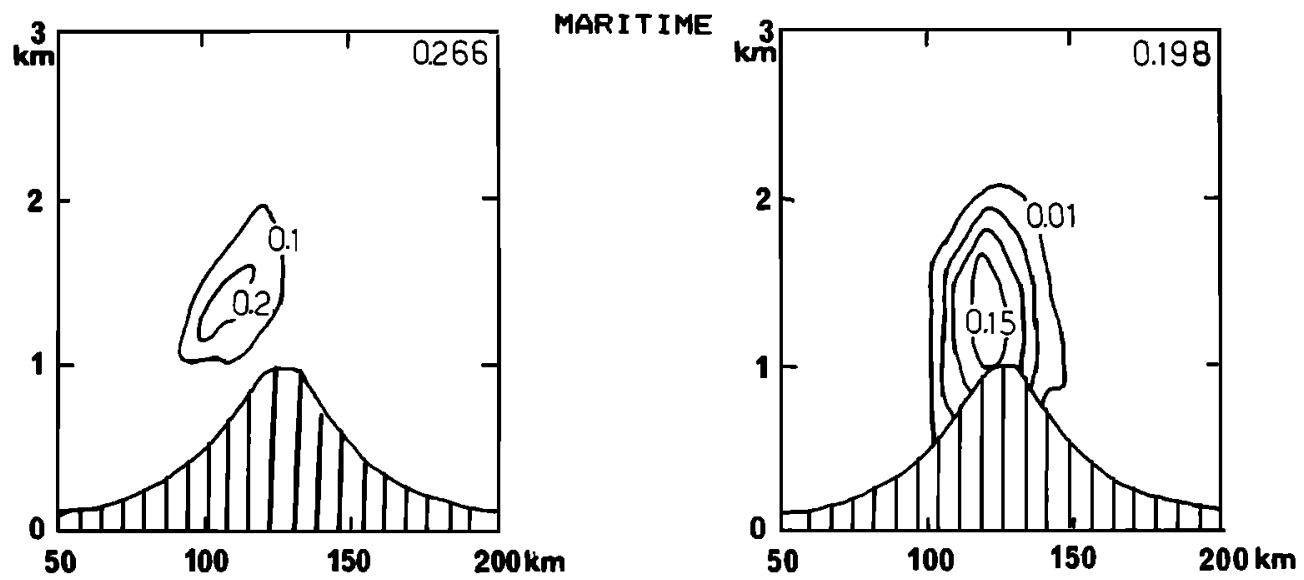

Fig. 5. Vertical cross sections of (a) cloud water mixing ratio and $(b)$ rain water mixing ratio after 6-hour model time in continental and maritime cases. The maxima values of $q_{c w}$ and $q_{r w}$ are reported in the right corner of each figure.

(Figure $7 a$ ) and the run including all the scavenging processes (Figure $7 b$ ). There is 1-2 orders of magnitude difference between the results of the simulations with and without nucleation in continental and maritime cases, respectively. The continental cloud is more efficient for in-cloud scavenging (Figure 7) and the contribution of scavenging by Brownian and turbulent diffusion (Figure $7 a$ ) is not completely negligible for small cloud droplets which are apt to collect aerosols of radii less than $0.1 \mu \mathrm{m}$. This has already been suggested by Garland [1978]. On the contrary, maritime clouds are much more efficient for removing aerosols (Figure 8), even when the nucleation term has been omitted (Figure $8 a$ ). This is essentially due to the predominance of autoconversion in the initiation of the rain process in maritime conditions. As already underlined, it can be inferred that sulfate wet deposition will be more effective in the case of maritime cloud. This will be discussed later, in section 3.5 .

\subsection{Gas Scavenging Results}

Before studying sulfate deposition, $\mathrm{SO}_{2}$ dissolution and oxidation by $\mathrm{H}_{2} \mathrm{O}_{2}$ and $\mathrm{O}_{3}$ and its subsequent transformation to sulfates must be considered.

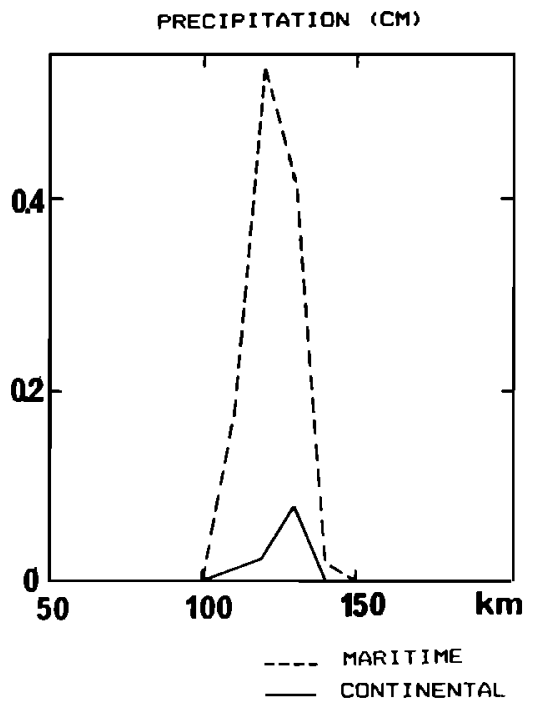

Fig. 6. Precipitation amount (in centimeters) cumulated over a 6-hour period for continental (solid line) and maritime clouds (dashed line). 


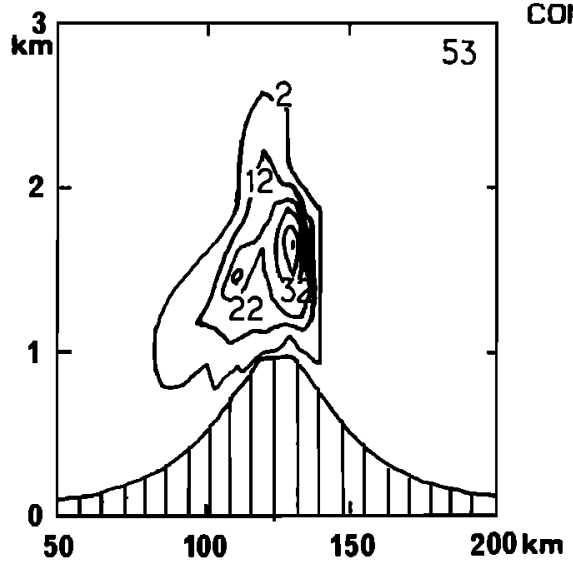

CNT I NENTAL

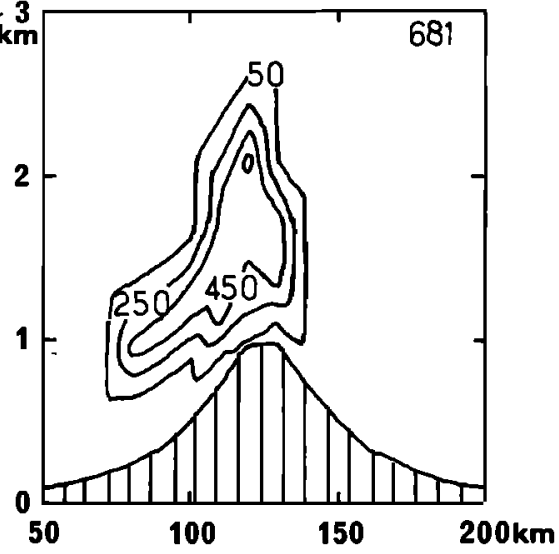

IN-CLOUD AEROSOL CONCENTRATION (N/CM:)

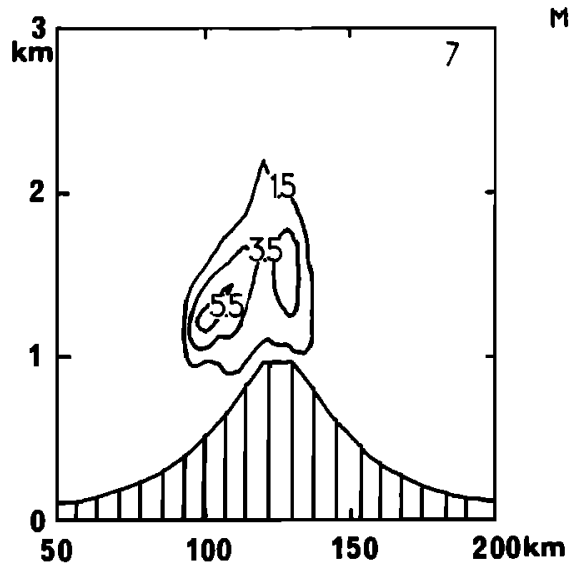

WI THOUT NUCLEATION
MARI I IME

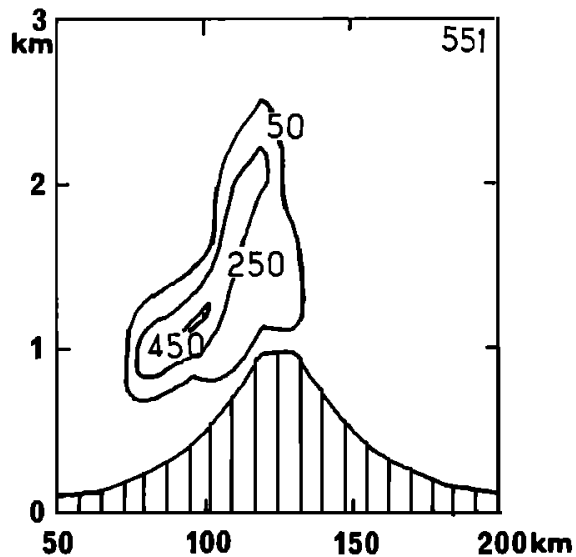

Fig. 7. Vertical cross sections of in-cloud aerosol concentration $C_{c p}$ (in number per cubic centimeter) in continental and maritime clouds $(a)$ without nucleation and $(b)$ with nucleation. The maximum value of $C_{c p}$ is reported in the right corner of each figure.

Results of sensitivity tests are first presented in order to study the relative impact of $\mathrm{O}_{3}$ and $\mathrm{H}_{2} \mathrm{O}_{2}$ oxidation on the conversion of $\mathrm{SO}_{2}$ into sulfate particles. Vertical cross sections of $\mathrm{SO}_{2}$ mixing ratio after oxidation by ozone (Figure $9 a$ ) and after oxidation by both $\mathrm{O}_{3}$ and $\mathrm{H}_{2} \mathrm{O}_{2}$ (Figure $9 b$ ) have been superimposed on vertical cross sections, for which only advection effects have been considered (dashed isocontours in Figure 9). Clear $\mathrm{SO}_{2}$ depletion coinciding with the presence of cloud (shaded zones) is observed in Figure 9 when oxidation occurs. The reduction in $\mathrm{SO}_{2}$ mixing ratio is even greater when considering simultaneous oxidation by $\mathrm{O}_{3}$ and $\mathrm{H}_{2} \mathrm{O}_{2}$ (Figure $9 b$ ) than when considering oxidation by $\mathrm{O}_{3}$ only (Figure 9a). If we now focus (Figure 10) on the time evolution of $\mathrm{SO}_{2}$ mixing ratio, the oxidation by $\mathrm{H}_{2} \mathrm{O}_{2}$ appears to occur quite rapidly (after about half an hour model time), after which slower oxidation by $\mathrm{O}_{3}$ takes place for several hours.
Oxidation by $\mathrm{H}_{2} \mathrm{O}_{2}$ is initially fast and leads to a rapid decrease in cloud water $\mathrm{pH}$; however, it cannot be sustained past the first few minutes of cloud because of $\mathrm{H}_{2} \mathrm{O}_{2}$ depletion. The $p \mathrm{H}$ was initially set to 5 ; it falls down to a value less than 4 . When only oxidation by $\mathrm{O}_{3}$ occurs, the $p \mathrm{H}$ is not very much affected and differences between curves 2 and 3 in Figure 10 can be explained by the fact that $\mathrm{O}_{3}$ contribution to sulfate formation is more efficient when the $p \mathrm{H}$ is greater than 4 [Hoffmann and Jacob, 1984; Seigneur and Saxena, 1984].

Surprisingly, we did not find any striking difference between maritime and continental clouds as regards the $\mathrm{SO}_{2}$ mixing ratios after oxidation in the aqueous phase. Presumably, some compensating effect arises between the dynamical and physicochemical processes leading to such a similarity. In order to identify which ones of those processes are balancing each other we first try to switch off dynamical/microphysical inter- 

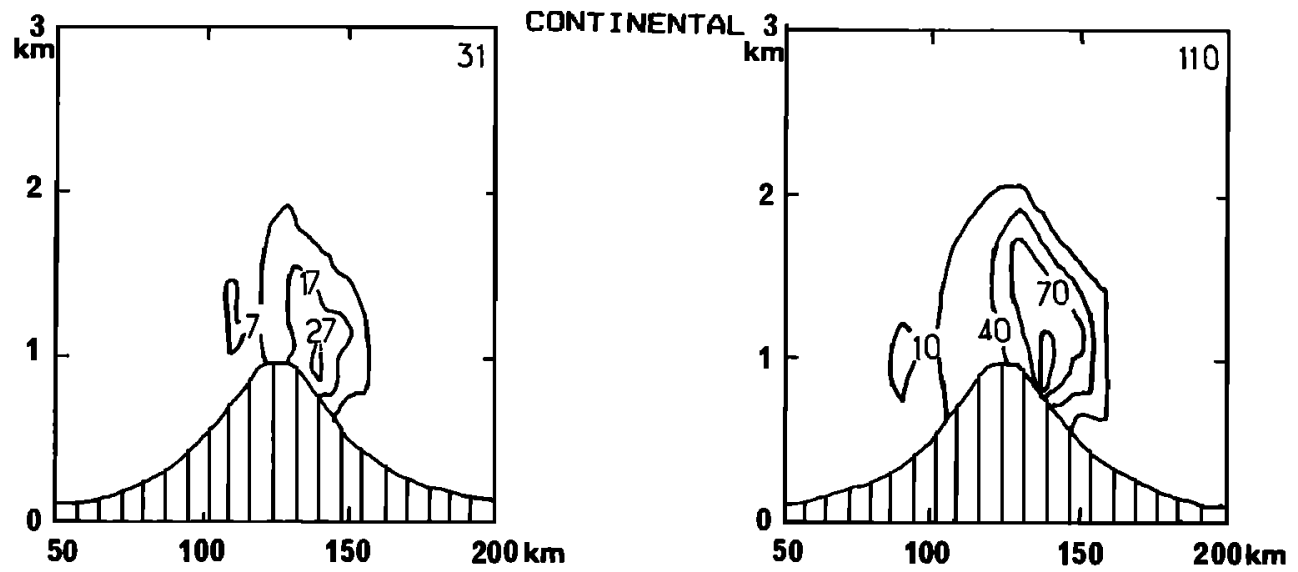

REMOUED AEROSDL CONCENTRATION (N/CMB)

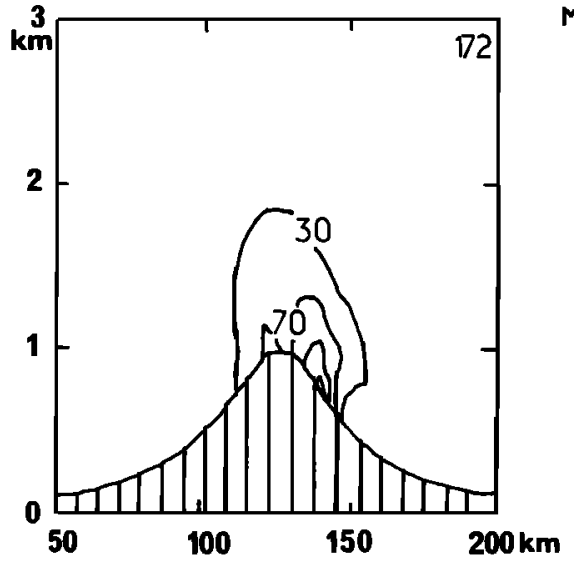

WI THOUT NUCLEATION

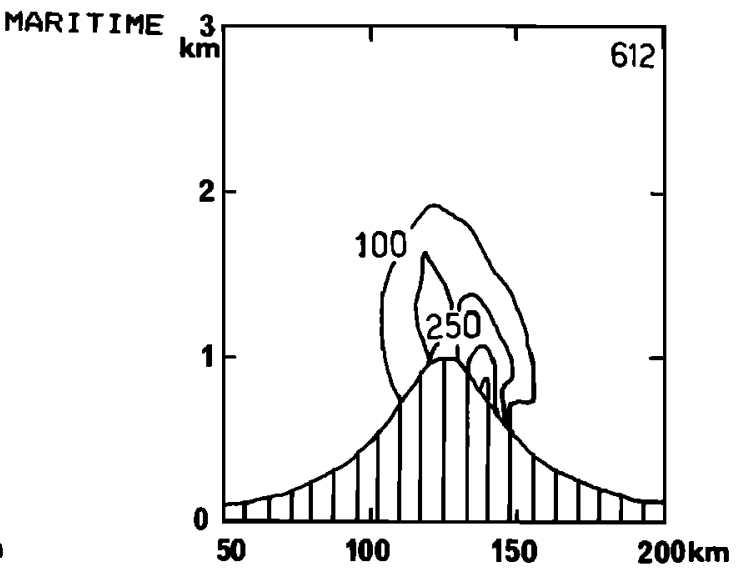

WITH NUCLEATION

Fig. 8. Same as Figure 7, but for removed aerosol concentration $C_{r p}$.

actions in the model by setting to zero the term of latent heat release in (1). Thus the dynamical conditions of Figure $3 a$ are artificially imposed on the continental and maritime clouds. Figure 11 displays the vertical cross sections of the $\mathrm{SO}_{2}$ mixing ratio for both clouds. The continental cloud is more efficient than the maritime one for $\mathrm{SO}_{2}$ scavenging. Clearly, a rapid $\mathrm{SO}_{2}$ disappearance occurs as the cloud begins to form in the zone where condensation processes act upwind of the mountain top. The differences observed in the $\mathrm{SO}_{2}$ fields can be attributed to smaller continental droplets with longer residence times than maritime cloud ones [Hong and Carmichael, 1983; Chameides, 1984].

\subsection{Sulfate Deposition}

Deposition is the ultimate stage in a chain of very complex interactions between pollutants, winds, clouds, and rain. It represents a concrete and measurable parameter useful in comparative studies. In Figure 12, comparative tests are synthesized in the form of wet sulfate deposition (in micrometers) accumulated over a 6-hour period. The amount of deposited sulfate is larger in the maritime case (Figure 12b) than in the continental one (Figure 12a). The shift in the maxima of sulfate deposition between the two cases is probably associated with the precipitation drift already discussed in section 2.2). Another test which has been performed bears upon the sensitivity of sulfate deposition to $\mathrm{SO}_{2}$ oxidation in aqueous phase. The foremost observation in Figure 12, by comparing dashed lines with solid lines, is that the $\mathrm{SO}_{2}$ scavenging only accounts for a small fraction of the overall pollutant deposition in the continental case. It looks more important in the maritime case, for which it is about one third of the overall sulfate deposition in the first 2 hours of the simulation (Figure 12b). 

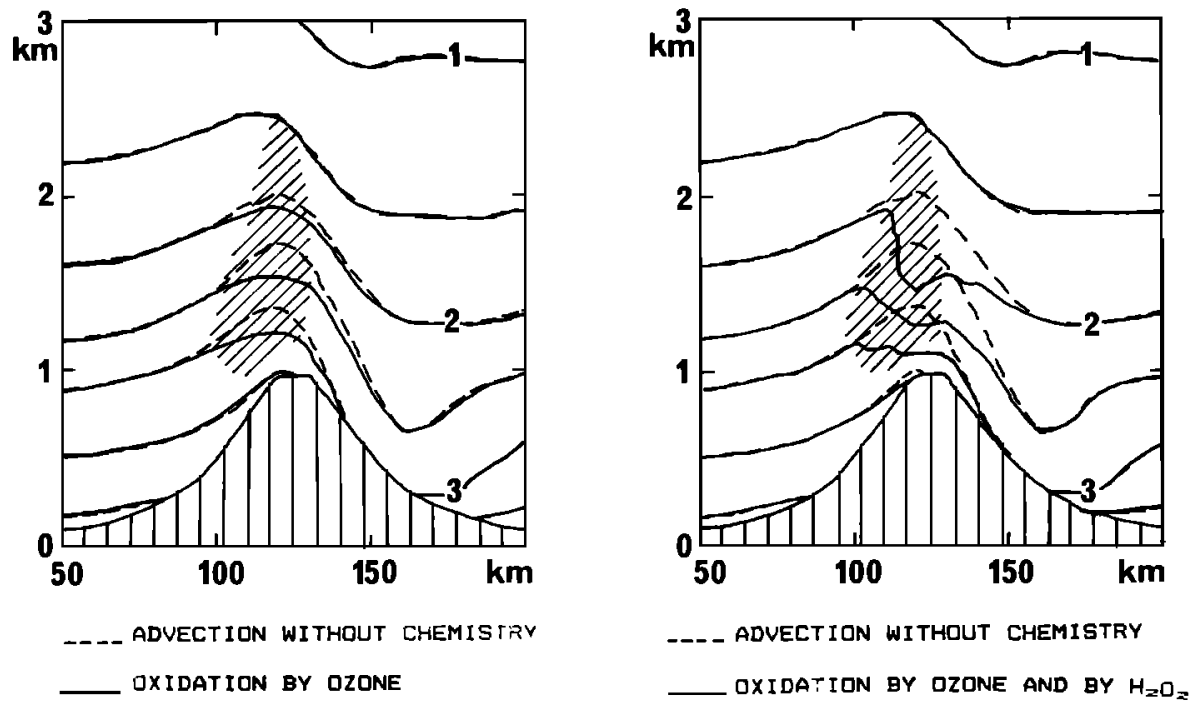

F1g. 9. Vertical cross sections of the $\mathrm{SO}_{2}$ mixing ratio in maritime clouds after 0.5 hour: (a) without chemistry (dashed line) and with oxidation by ozone (solid line), $(b)$ without chemistry (dashed line) and with oxidation by $\mathrm{H}_{2} \mathrm{O}_{2}$ and ozone (solid line). Shaded zones show the presence of cloud water. The vertical and horizontal scales are indicated.

The differences in Figure $12 b$ are more obvious at the beginning of the simulation because of the oxidation effect of $\mathrm{H}_{2} \mathrm{O}_{2}$, which acts during the cloud formation.

\section{Conclusions}

A quasi-spectral parameterization for liquid water (both cloud water and rainwater) has been included in the framework of a mesoscale model to quantify the interactive processes at work in pollutant wet removal.

First, sensitivity tests have been performed to establish the following hierarchy among physicochemical processes. Nucleation scavenging has been found to be the most efficient in-cloud scavenging process. Its computation requires knowledge of an explicit nucleation rate and is a function of supersaturation and cloud spectrum. During the cloud formation a

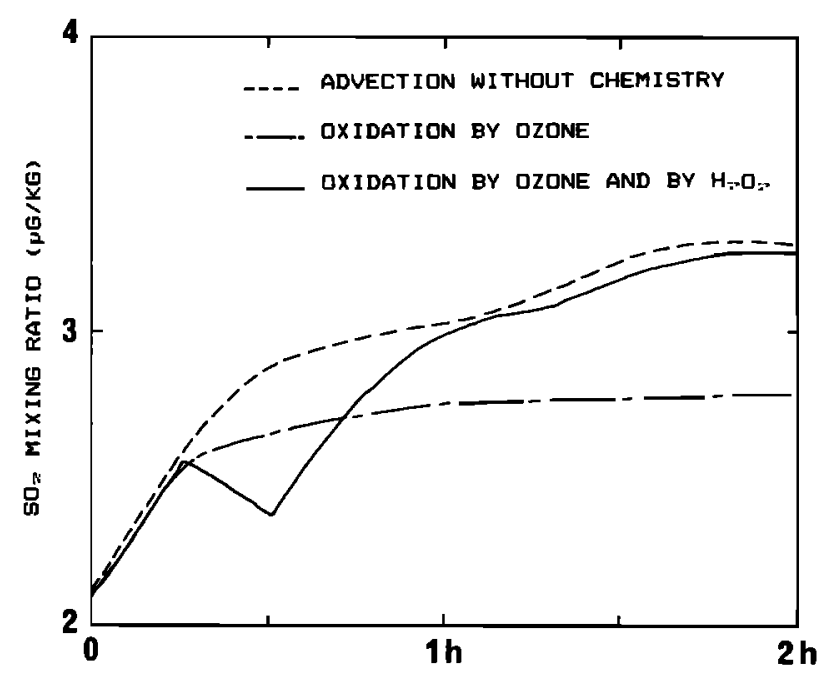

Fig. 10. Temporal evolution of $\mathrm{SO}_{2}$ mixing ratio over 2-hour period at $x=110 \mathrm{~km}$ and $z=150 \mathrm{~m}$ for three sensitivity tests: (a) without chemistry, $(b)$ with oxidation by ozone, and $(c)$ with oxidation by ozone and $\mathrm{H}_{2} \mathrm{O}_{2}$. part of total wet deposition is due to $\mathrm{SO}_{2}$ scavenging, which itself is dependent upon the liquid water content and the droplet sizes. It should be emphasized that the spectral information given by our microphysical scheme is well suited to the treatment of $\mathrm{SO}_{2}$ dissolution and oxidation in liquid phase, due to detailed representation of the condensation/evaporation processes. In addition, Brownian and turbulent diffusions may significantly contribute to in-cloud scavenging, in the case of small continental droplets capturing particles with radii less than $0.1 \mu \mathrm{m}$. Through its quasi-spectral treatment of both hydrometeors and aerosols, the model has the ability to duplicate such effects.

The second point to be emphasized is the methodology adopted for studying typical continental and maritime clouds through idealized tests. In the mesoscale, simultaneous col-

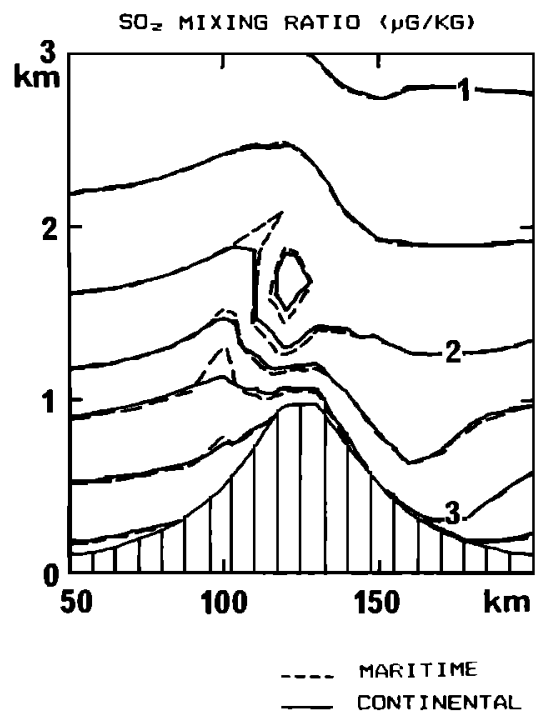

Fig. 11. Vertical cross sections of $\mathrm{SO}_{2}$ mixing ratio for maritime (dashed lines) and continental (solid lines) clouds after 0.5 hour, with oxidation by $\mathrm{H}_{2} \mathrm{O}_{2}$ and ozone. Latent heat release effects have been removed. 


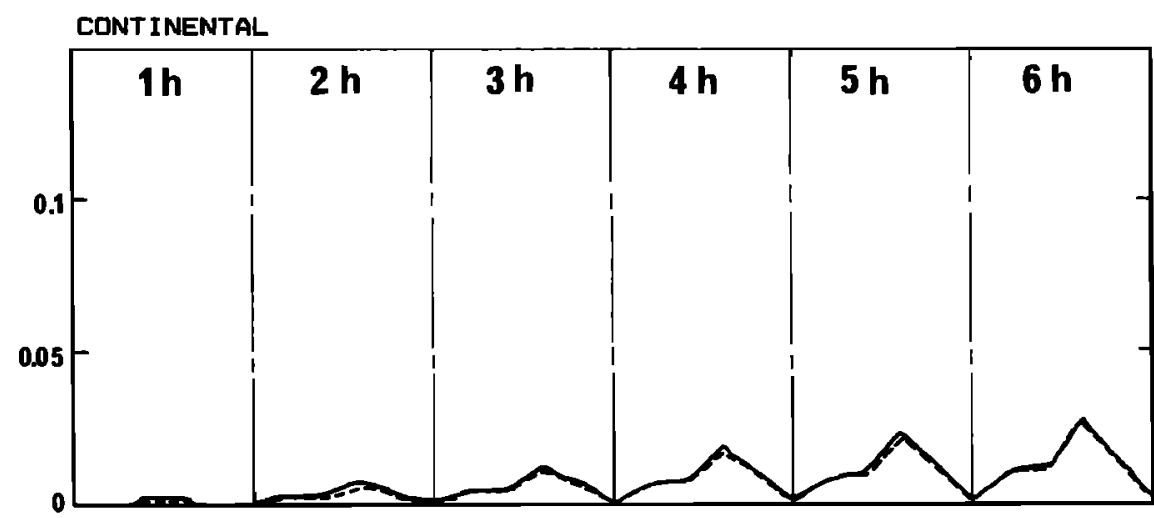

WITHOUT CHEMISTRY

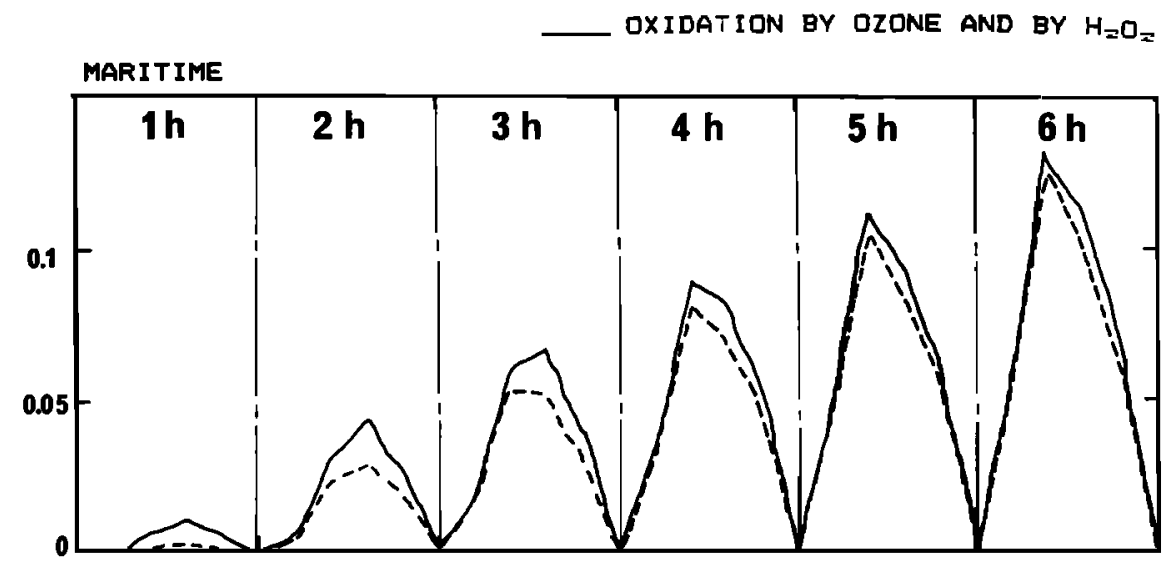

Fig. 12. Temporal evolution of sulfate wet deposition on the mountain top over 6-hour period for continental versus maritime cases for two sensitivity runs: (a) without chemistry (dashed lines) and (b) with oxidation by ozone and $\mathrm{H}_{2} \mathrm{O}_{2}$ (solid lines).

lection of meteorological and physicochemical data is difficult to carry out experimentally. The results of this study suggest that a comprehensive numerical model could be effective in isolating the underlying interactions of winds, microphysics, and physicochemistry and should be able to discriminate between their relative effects. This can be of use in defining experimental strategies or in interpreting data. Sulfate deposition is very sensitive to the cloud type: in-cloud scavenging is favored in continental clouds, while precipitating maritime clouds remove particles more efficiently. Here only very simple chemistry has been incorporated in the mesoscale model. In particular, a ionic balance equation should be included in the model in order to have more consistency between the $p \mathrm{H}$ and the sulfate particle population. Also, because of its explicit representation of the cloud droplet size distribution, the effect of mass transport limitations on $\mathrm{SO}_{2}$ aqueous-phase oxidation will be studied in the future.

\section{APPENDIX: LIST OF SYMBOLS}

$C$ empirical constant $\left(3500 \mathrm{~cm}^{-3}\right.$ in continental case, 100 in maritime case).

$C_{a p}$ dry aerosol concentration.

$C_{a p \cdot \text { nuc }}$ number of aerosols activated through nucleation during one time step.
$C_{c p}$ cloud water aerosol concentration

$C_{p}$ specific heat at constant pressure for dry air.

$C_{p m}$ specific heat at constant pressure for moist air.

$C_{r p}$ removed aerosol concentration.

$D_{c}$ cloud droplet diameter.

$D_{c o}$ distribution parameter for the lognormal cloud droplet distribution.

$D_{\text {crit }}$ minimum critical diameter of (soluble) particles activated at supersaturation $S_{\max }$.

$D_{r}$ raindrop diameter.

$D_{r 0}$ distribution parameter for the lognormal raindrop distribution.

$D_{v}$ water vapor diffusivity.

$F_{X}$ friction terms relative to any prognostic variable $X$.

$K$ thermal conductivity.

$K_{H}$ horizontal diffusion coefficient.

$L_{v}$ vapor latent heat.

$N$ cloud condensation nucleus concentration.

$N_{c w}$ cloud droplet concentration.

$N_{\text {nuc }}$ number of cloud droplets nucleated during one time step.

$N_{r w}$ raindrop concentration.

$P$ Pressure.

$P_{0}$ reference pressure (1013 mbar). 
$P_{s}$ pressure at the lower boundary.

$P_{T}$ pressure at the top boundary.

$\hat{P}=\left(P / P_{0}\right)^{\kappa}$.

$R$ specific gas constant for dry air.

Re Reynolds number.

$R_{w} \quad$ specific gas constant for moist air.

$S$ supersaturation.

Sc Schmidt number.

$S_{n}$ sedimentation flux of raindrops.

$S_{\max }$ maximal supersaturation.

$T$ temperature.

$X=R e^{1 / 2} S c^{1 / 3}$.

$e_{s w}$ saturation vapor pressure over plane water surface.

$\bar{f}$ ventilation factor.

$g$ acceleration of gravity.

$i$ Van't Hoff coefficient for nonideal aqueous salt solution $(=3)$.

$k$ empirical constant ( 0.9 in continental case, 0.7 in maritime case)

$m$ nucleus mass.

$m_{N}$ molecular weight of salt $\left(=132.1 \times 10^{-3}\right.$ for $\left.\left(\mathrm{NH}_{4}\right)_{2} \mathrm{SO}_{4}\right)$.

$m_{w}$ molecular weight of water.

$q_{a p}$ dry aerosol volume mixing ratio.

$q_{a p \cdot \text { nuc }}$ volume mixing ratio of aerosols activated through nucleation during one time step.

$q_{c p}$ cloud water aerosol volume mixing ratio.

$q_{c w}$ cloud water mixing ratio.

$q_{d s} \quad \mathrm{SO}_{2}$ mixing ratio.

$q_{\text {nuc }}$ mixing ratio for cloud droplets nucleated during one time step.

$q_{r p}$ removed aerosol volume mixing ratio.

$q_{r w}$ rainwater mixing ratio.

$q_{v}$ vapor mixing ratio.

$q_{v s}$ saturation vapor mixing ratio.

$r_{\text {nuc }}$ nucleus radius.

$t$ time.

$x$ horizontal west-east coordinate.

$y$ horizontal south-north coordinate.

$z$ altitude.

$\beta$ beta function;

$\beta(a, b)=\int_{0}^{1} x^{a-1}(1-x)^{b-1} d x$.

$\varepsilon$ constant $(=0.623)$

$\rho_{a}$ density of air.

$\rho_{w}$ density of water.

$v$ vertical coordinate defined by $\sigma=\left(4 v-v^{4}\right) / 3$.

$\dot{v}$ vertical velocity.

$\pi$ constant $(=3.141592653)$.

II ground pressure $\left(=P_{s}-P_{T}\right)$

$\kappa$ constant $(=2 / 7)$.

$\sigma$ pressure coordinate defined by $\sigma=\left(P-P_{T}\right) / \Pi$.

$\sigma^{\prime} d \sigma / d v$.

$\sigma_{c}$ dispersion parameter for lognormal cloud droplet distribution ( 0.15 for continental cloud and 0.28 for maritime cloud).

$\sigma_{r}$ dispersion parameter for lognormal raindrop distribution $(=0.5)$.

$\Theta$ potential temperature.

Acknowledgments. The authors would like to express their gratitude to P. Mascart for his support and encouragement and R. Rosset for his helpful comments and suggestions. This work was supported by lunds from Electricite de France and the authors gratefully acknowledge their support. The computer simulations were performed with the support and assistance of Centre de Calcuf Vectoriel pour la Recherche, Palaiseau, France, project 3736, the European Center for Medium Range Weather Forecasts, Reading, England, and also Météorologie Nationale, Paris.

\section{REFERENCES}

Asselin, R., Frequency filter for time integrations, Mon. Weather Rev., 100, 487-490, 1972

Berry, E. X., and R. L. Reinhardt, Modeling of condensation and collection within clouds, Desert Res. Inst. Phys. Sci. Publ., 16, Univ. of Nev., 1973.

Chameides, W. L., The photochemistry of a remote marine stratiform cloud, J. Geophys., Res., 89, 4739-4755, 1984.

Chaumerliac, N., E. C. Nickerson, and R. Rosset, A 3D mesoscale model as a potential tool for the evaluation of sulfate particles scavenging, Ann. Geophys., Ser. B, 4(3), 345-352, 1986.

Dana, J., and J. M. Hales, Statistical aspects of the washout of polydisperse aerosols, Atmos. Environ., 10, 45-50, 1976.

Dingle, A. N., and Y. Lee, An analysis of in-cloud scavenging, J. Appl. Meteorol., 12, 1295-1302, 1973.

Durran, D. R., and J. B. Klemp, A comprehensive model for the simulation of moist mountain waves, Mon. Weather Rev., 111, 2341-2361, 1983.

Flossman, A. I., W. D. Hall, and H. R. Pruppacher, A theoretical study of the wet removal of atmospheric pollutants, I, The redistribution of aerosol particles captured through nucleation and impaction scavenging by growing cloud drops, J. Atmos. Sci., 42, 583$606,1985$.

Garland, J. A., Dry and wet removal of sulphur from the atmosphere, Atmos. Environ., 12, 349-362, 1978.

Georgii, H. W., Large-scale spatial and temporal distribution of sulphur compounds, Atmos. Environ., 12, 681-690, 1978.

Georgii, H. W., and F. X. Meixner, Measurement of the tropospheric and stratospheric $\mathrm{SO}_{2}$ distribution, J. Geophys. Res., 85, 7433-7438, 1980.

Hegg, D. A., P. V. Hobbs, and L. F. Radke, Measurements of the scavenging of sulfate and nitrate in clouds, Atmos. Environ., 18, 1939-1946, 1984a.

Hegg, D. A., S. A. Rutledge, and P. V. Hobbs, A numerical model for sulfur chemistry in warm-frontal rainbands, J. Geophys. Res., 89, 7133-7147, 1984b.

Hoffmann, M. R., and D. J. Jacob, Kinetics and mechanisms of the catalytic oxidation of dissolved sulfur dioxide in aqueous solution: An application to nighttime fog water chemistry, in $\mathrm{SO}_{2}, \mathrm{NO}$, and $\mathrm{NO}_{2}$ Oxidation Mechanisms: Atmospheric Consideration, edited by J. G. Calvert, 101-172, Butterworth, Stoneham, Mass., 1984.

Hong, H. S., and G. R. Carmichael, An investigation of sulfate production in clouds using a flow-through chemical reactor model approach, J. Geophys. Res., 88, 10,733-10,743, 1983.

Jensen, J. B., and R. J. Charlson, On the efficiency of nucleation scavenging, Tellus, 36B, 367-375, 1984.

Kitada, T., G. R. Carmichael, and L. K. Peters, Numerical simulation of the transport of chemically reactive species under land and sea breeze circulations, J. Clim. Appl. Meteorol., 23, 1153-1172, 1984.

Klemp, J. B., and D. K. Lilly, Numerical simulation of hydrostatic waves, J. Atmos. Sci., 35, 78-107, 1978.

Lee, I. Y., and H. R. Pruppacher, A comparative study on the growth of cloud drops by condensation using an air parcel model with and without entrainment, Pure Appl. Geophys., 115, 523-545, 1977.

Maahs, H. G., Kinetics and mechanisms of the oxidation of S(IV) by ozone in aqueous solution with particular reference to $\mathrm{SO}_{2}$ conversion in nonurban tropospheric clouds, J. Geophys. Res., 88, 10,721$10,732,1983$.

Mahrer, Y., and R. A. Pielke, A test of an upstream spline interpolation technique for the advective terms in a numerical mesoscale model, Mon. Weather Rev., 106, 818-830, 1978.

Martin, L. R., Acid Precipitation, in $\mathrm{SO}_{2}, \mathrm{NO}$, and $\mathrm{NO}_{2}$ Oxidation Mechanisms: Atmospheric Considerations, edited by J. G. Calvert, p. 63-100, Butterworth, Stoneham, Mass., 1984.

Nickerson, E. C., On the numerical simulation of airflow and clouds over mountainous terrain, Contrib. Atmos. Phys., 52, 161-177, 1979.

Nickerson, E. C., E. Richard, R. Rosset, an D. R. Smith, The numerical simulation of clouds, rain, and airflow over the Vosges and Black Forest Mountains: A meso-model with parameterized microphysics, Mon. Weather Rev., 114, 398-414, 1986. 
Orlanski, I., A simple boundary condition for unbounded hyberbolic flows, J. Comput. Phys., 21, 251-269, 1976.

Prodi, F., and F. Tampieri, The removal of particulate matter from the atmosphere: the physical mechanisms, Pure Appl. Geophys., 120, 286-325, 1982.

Pruppacher, H. R., and J. D. Klett, Microphysics of Clouds and Precipitation, 714 pp., D. Reidel, Hingham, Mass., 1978.

Pruppacher, H. R., and R. A. Rasmussen, A wind tunnel investigation of the rate of evaporation of large water drops falling at terminal velocity in air, J. Atmos. Sci., 36, 1255-1260, 1979.

Radke, L. F., Preliminary measurements of the size distribution of cloud interstitial aerosol, Precipitation Scavenging, Dry Deposition and Resuspension, edited by H. R. Pruppacher, R. G. Semonin, and W. G. N. Slinn, pp. 71-89, Elsevier, New York, 1983.

Sakakibara, H., A scheme for stable numerical computation of the condensation process with large time step, J. Meteorol. Soc. Jpn., 57, 349-353, 1979.

Seigneur, C., and P. Saxena, A study of atmospheric acid formation in different environments, Atmos. Environ., 18, 2109-2124, 1984.

Squires, $P$., The microstructure and colloidal stability of warm clouds, I, The relation between structure and stability, Tellus, 10, 256-271, 1958.
Tremblay, A., and $\mathbf{H}$. Leighton, The influence of cloud dynamics upon the redistribution and transformation of atmospheric $\mathrm{SO}_{2}$ : A numerical simulation, Atmos. Environ., 18, 1885-1894, 1984.

Twomey, S., The nuclei of natural cloud formation, II, The supersaturation in natural clouds and the variations of cloud droplet concentration, Geofis. Pura Appl., 43, 243-249, 1959.

N. Chaumerliac, E. Richard, and J.-P. Pinty, Laboratoire Associe de Meteorologie Physique, Observatoire de Physique du Globe de Clermont-Ferrand, Université de Clermont II, Laboratoire Associe Centre National de la Recherche Scientifique No. 267, B. P. 45, 63170, Aubière, France.

E. C. Nickerson, National Oceanic and Atmospheric Administration Environmental Research Laboratories, GMCC/R/E/AR 4, 325 Broadway, Boulder, CO 80303.

(Received January 3, 1986;

revised November 24,1986 accepted December 1, 1986.) 